\title{
Behavior of Concrete Columns Repaired with Polymer Mortar and Epoxy Fiber Panel
}

\author{
Sungnam Hong and Sun-Kyu Park \\ Department of Civil and Environmental Engineering, Sungkyunkwan University, Suwon 440-746, Republic of Korea \\ Correspondence should be addressed to Sun-Kyu Park; skpark@skku.edu
}

Received 12 November 2012; Accepted 30 January 2013

Academic Editor: Md Mainul Islam

Copyright ( 12013 S. Hong and S.-K. Park. This is an open access article distributed under the Creative Commons Attribution License, which permits unrestricted use, distribution, and reproduction in any medium, provided the original work is properly cited.

Underwater structures are not easy to check for the degree of damage or to repair and strengthen damaged regions. Even during repair and strengthening, quality control is very difficult, because the work is done under water. Moreover, underwater structures severely deteriorate, owing to special environmental conditions. If this deterioration continues, the structures face serious structural problems, because of the corrosion of steel rods and the loss of concrete sections. Repairing or strengthening underwater structures requires effective, economic underwater repair and reinforcement techniques that allow the same working conditions as on the ground while maintaining dry condition for the repair sections. However, systematic studies on the repair and strengthening techniques for underwater structures are insufficient. This study proposes a new repair method for underwater structures, which applies epoxy fiber panel forms and shear connectors. To demonstrate the repair effects, this study compared and evaluated the failure modes and repair effects by the surface condition of repair sections, by applying various repair methods, in consideration of the ground and underwater conditions.

\section{Introduction}

When concrete structures are constructed in a river, lake, or sea, a part of the structure is placed under water, and the underwater structures are subjected to damages such as concrete spalling and exfoliation, due to aging, faulty construction, and various deterioration factors [1]. Such structures urgently need repairs and reinforcements. In particular, the substructures of bridges in water are subjected to damages by such environmental factors as the scouring of foundations by water flow, erosion of members, and the corrosion of steel rods [2], in addition to the damages that may occur to structures above ground.

Structural engineers have extensive experience of repairing concrete structures above water [3-6]. The conventional approach to the repair of reinforced concrete columns that have shallow damages, however, is to use patch repair for the damaged zones where cracking and spalling occur $[7,8]$. For patch repair to be structurally effective, the appropriate material should be applied in the damaged concrete section.
A limited range of materials is available for use in underwater repair. They can be divided into two mortar types: cementitious and resin based. Generally, normal epoxy or polyester resins are unsuitable for underwater use, as they often fail to bond to the damaged concrete and can be adversely affected by reaction between the hardener and the water [9]. However, cementitious mortars can range from conventional mortars and grouts to materials with greatly enhanced properties achieved by the use of admixtures. In particular, the use of polymers can result in cohesiveness, high rates of strength gain, greater workability, resistance to washout of cement, and reduction in bleed and shrinkage [10-12]. From these advantages, polymer mortar has been utilized in a range of mortar and concrete repair and primary construction applications [13-15].

For effective repair and reinforcement of underwater structures, the damaged regions must be maintained in dry condition. However, installing coffers and caissons for partial defects under water requires a long period of work, much manpower, and heavy equipment, so causing much loss 


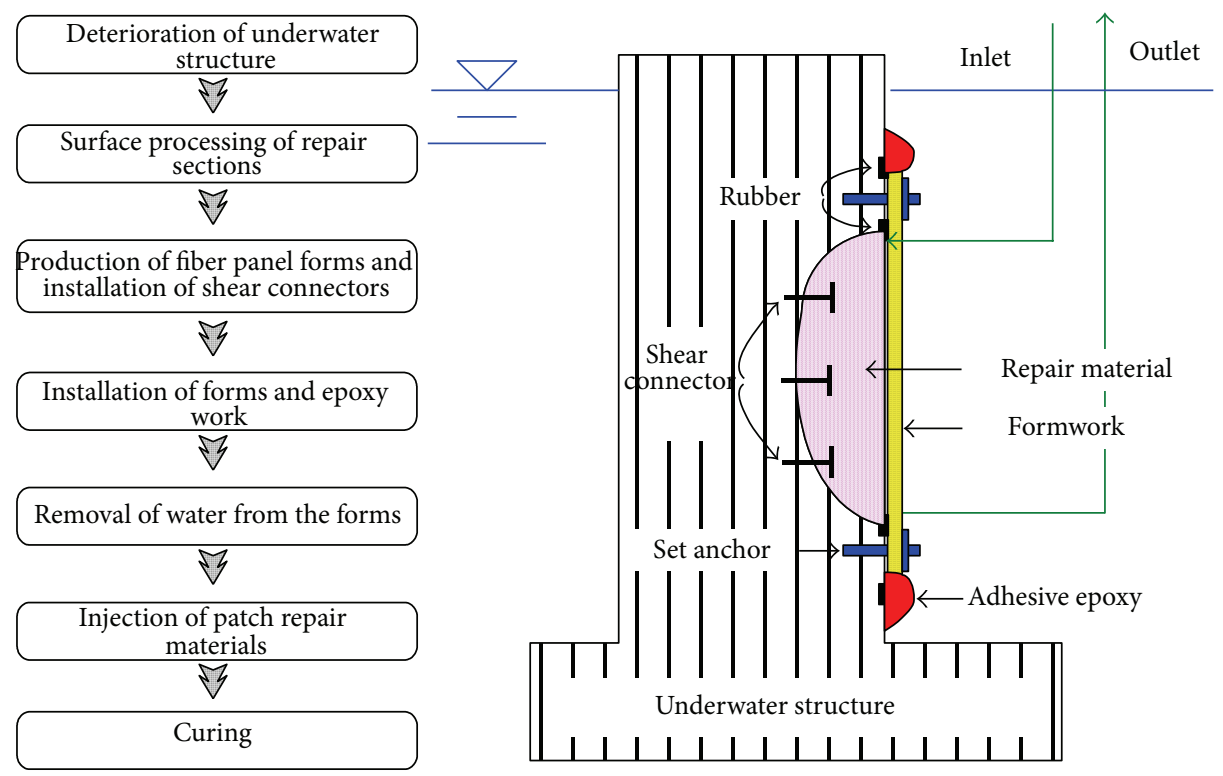

FIGURE 1: Schematic diagram of the newly proposed repair method.

in time and money [16]. Therefore, we need effective and economic underwater repair and reinforcement techniques that allow working in the same conditions as on the ground while maintaining a dry condition. However, systematic studies on the repairs and reinforcements of underwater structures are insufficient.

Accordingly, this study proposes a repair method for underwater structures, which applies epoxy fiber panel forms and shear connectors. To demonstrate the repair effects, this study compared and evaluated the repair effects, by applying various repair methods, in consideration of various underwater and ground conditions.

\section{Newly Proposed Underwater Repair Method}

Existing repair methods for underwater structures can be largely classified into three groups, as shown below [17].

(1) Repairing the damaged sections after installing coffers.

(2) Repairing by installing underwater caissons.

(3) Repairing with underwater repair materials by divers.

Repair methods that use coffers and caissons greatly increase time and construction cost, including materials cost, so they are uneconomical for partial repair works. Furthermore, the direct repair method by divers is also inappropriate, because it causes environmental problems such as the leakage of materials, quality control is difficult, and effective repair work is impossible.

The underwater repair method proposed by this study has been newly developed to apply to underwater structures with deteriorations such as concrete spalling and exfoliation, cracks, and corrosion of steel rods. Because the outside water is perfectly blocked by fiber panel forms, underwater epoxies, and rubber packings, while the damaged sections are repaired [18], this method maximizes the repair effects and enables economical work. Furthermore, the shear connectors installed on the repair sections give shear resistance at interfaces and prevent the elimination of repair materials; anchor bolts fix the forms, to provide binding force. The work procedure and a schematic diagram of the proposed underwater repair method are shown in Figure 1.

\section{Experimental Program}

3.1. Test Variables. To evaluate the performance of the proposed underwater repair method, control columns and repaired columns were produced, as shown in Table 1. The repaired columns were produced under water and above ground, to evaluate the effects of different working conditions. The proposed underwater repair method used the epoxy fiber panels and shear connectors in numbers 19 to 22 in Table 1.

It should be noted that the test columns were planned for the pilot test in the laboratory. Therefore, full-scale field tests should be conducted, to derive a general application for the proposed repair system.

3.2. Material Properties. The concrete mix proportion for the control and repaired columns are shown in Table 2. For the compressive strength and splitting tensile strength of concrete by atmospheric curing and water curing of concrete aged 28 days, three columns were produced and tested, and the mean values are summarized in Table 2.

For repair materials, inorganic polymer mortar with a polymer/cement ratio of $20 \%$, which was specially manufactured for underwater use, was used. The strength characteristics of the underwater repair material were determined by compressive strength test and splitting tensile strength test 


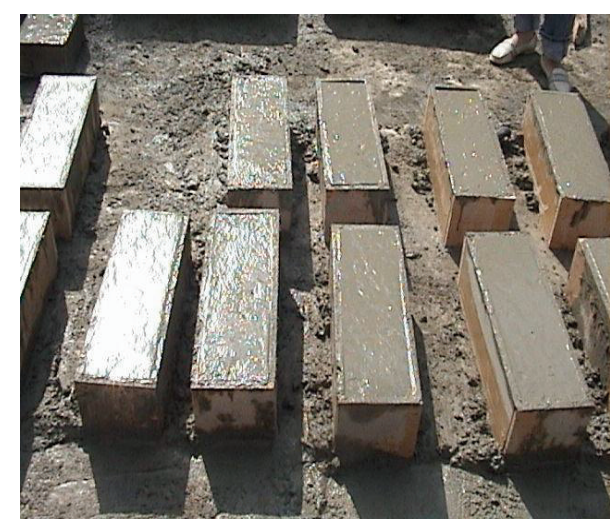

(a) Forms after pouring concrete

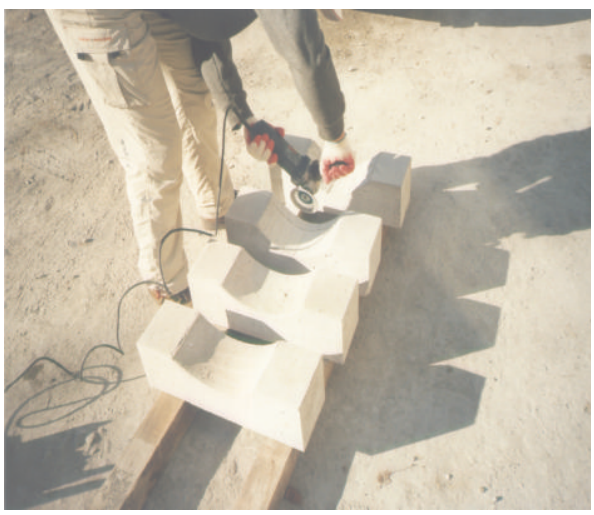

(c) Chipping of concrete

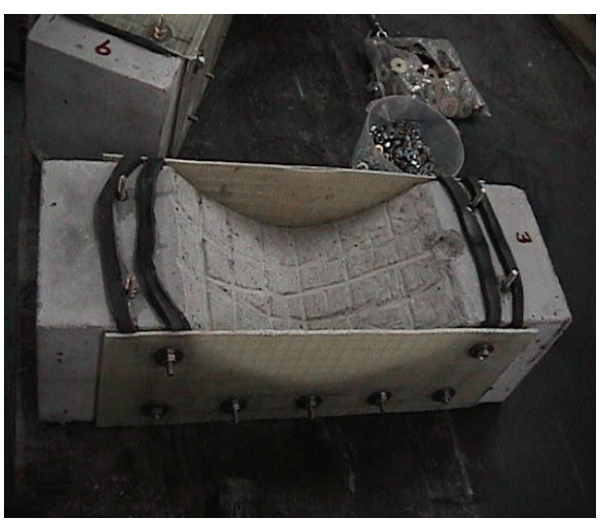

(e) Assembly of epoxy fiber panel

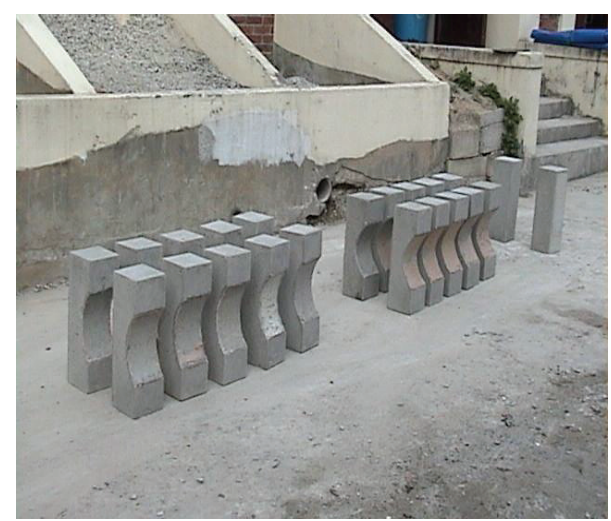

(b) Shape of columns

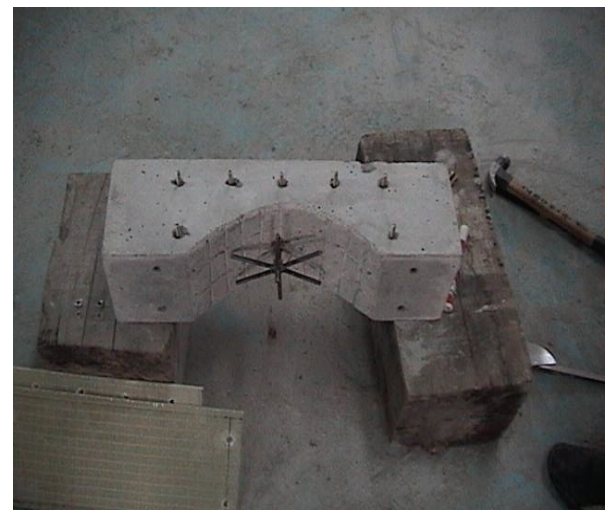

(d) Shear connectors and anchor bolts

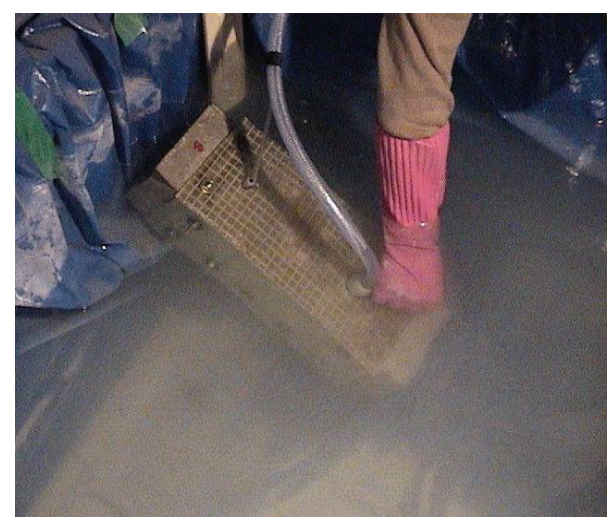

(f) Injection of repair materials

FIGURE 2: Column production process.

at the age of 28 days. The mean values of the three columns obtained from these tests are summarized in Table 3.

3.3. Production of Columns. For columns, control and repaired columns were produced under the assumption that the concrete was damaged as shown in Figure 2. The shape and dimensions of the sections of columns are shown in Figure 3. To obtain the repaired columns, two damaged columns whose depths of damage were $5 \mathrm{~cm}$ and $7 \mathrm{~cm}$ were repaired, in accordance with the test variables.
For G-D-D series columns, acrylic forms were attached to the sides of the repair sections on the ground, and underwater repair materials were injected in such a way that the repair materials would not flow out. For G-D-F-D series columns, epoxy fiber panel forms were fixed to the repair sections with anchors on the ground, and the underwater repair materials were injected through an inlet connected to the forms.

For U-W-F-D series columns, epoxy fiber panel forms were fixed under water, the gaps in the forms and columns were waterproofed using underwater epoxies, and underwater repair materials were injected without removing water 
TABLE 1: Variables of test columns.

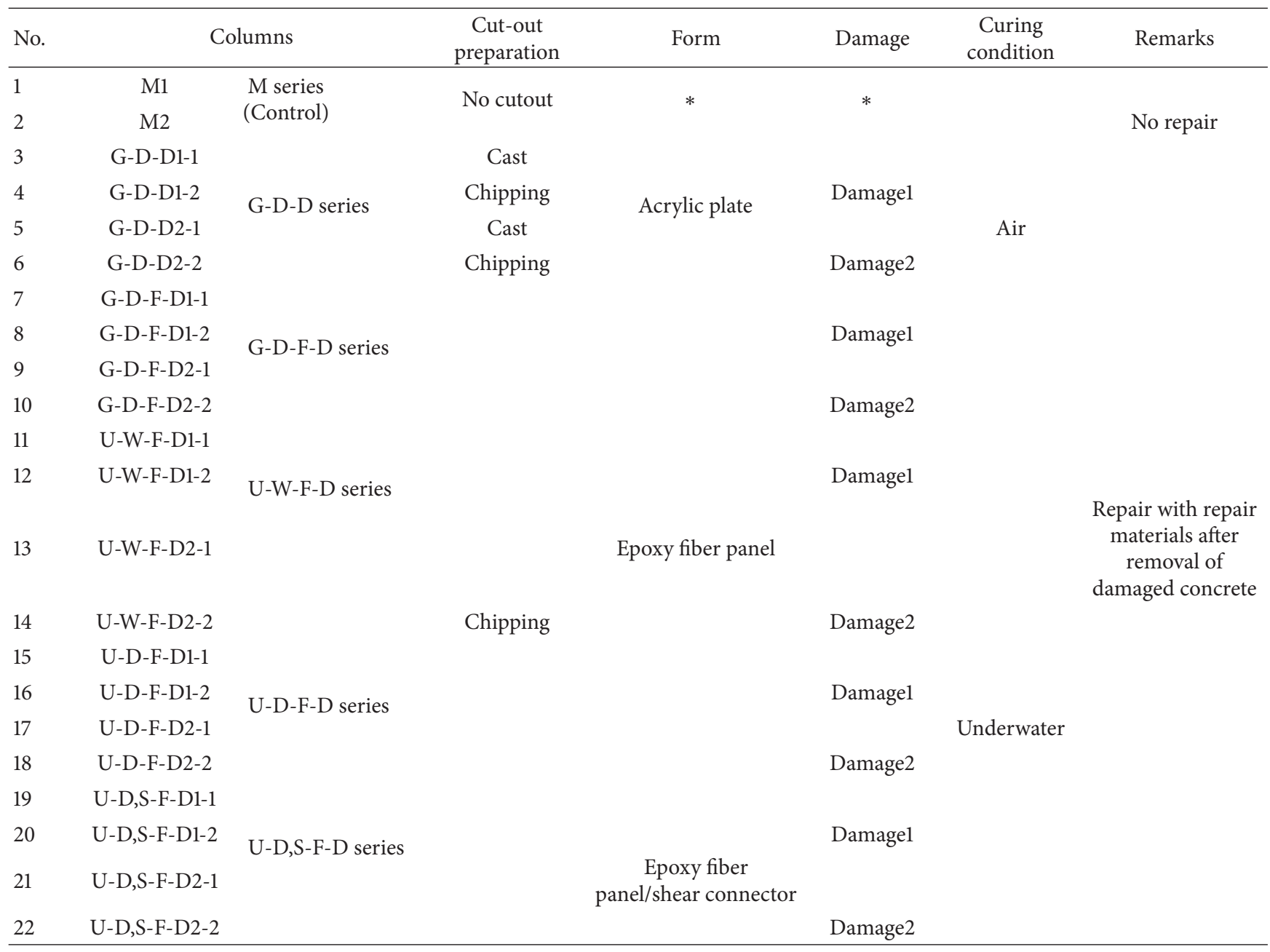

G: ground, U: underwater, D: dry, W: wet, S: shear connector, F: form (epoxy fiber panel), D1: damagel (depth $5 \mathrm{~cm})$, D2: damage2 (depth $7 \mathrm{~cm})$, and 1/2: serial number.

TABLE 2: Mix proportion and mechanical properties of concrete.

(a) Mix proportion

\begin{tabular}{lcccccc}
\hline \multirow{2}{*}{ Water/cement ratio (\%) } & \multicolumn{3}{c}{ Unit weight $\left(\mathrm{kg} / \mathrm{cm}^{3}\right)$} & \multicolumn{2}{c}{ Sand/aggregate ratio (\%) } \\
& Cement & Water & Fine aggregate & Coarse aggregate & Admixture & 47.5 \\
\hline 54.7 & 335 & 183 & 825 & 930 & 1.68 & 4.8 \\
\hline
\end{tabular}

(b) Mechanical properties

\begin{tabular}{lccc}
\hline Curing condition & Compressive strength $(\mathrm{MPa})$ & Tensile strength $(\mathrm{MPa})$ & Elastic modulus $(\mathrm{MPa})$ \\
\hline Atmospheric curing & 20.0 & 1.7 & 20901.2 \\
Water curing & 21.1 & 1.7 & 21604.6 \\
\hline
\end{tabular}

from the forms. For columns U-D-F-D series, epoxy fiber panel forms were fixed under water, the gaps in the forms and columns were waterproofed using underwater epoxies, water was removed from the forms, and then underwater repair materials were injected into them. For columns U-D,S-F-D series, anchors that play the role of shear connectors were inserted into the repair sections, the forms were fixed, water was removed, and the patch repair materials were injected.
All the columns were waterproofed for gaps in the forms and columns, using underwater epoxies after the forms were fixed.

3.4. Forms. The forms used in this experiment were manufactured with epoxy fiber panels with waterproof rubber packing. As shown in Figure 3, the repair sections were 

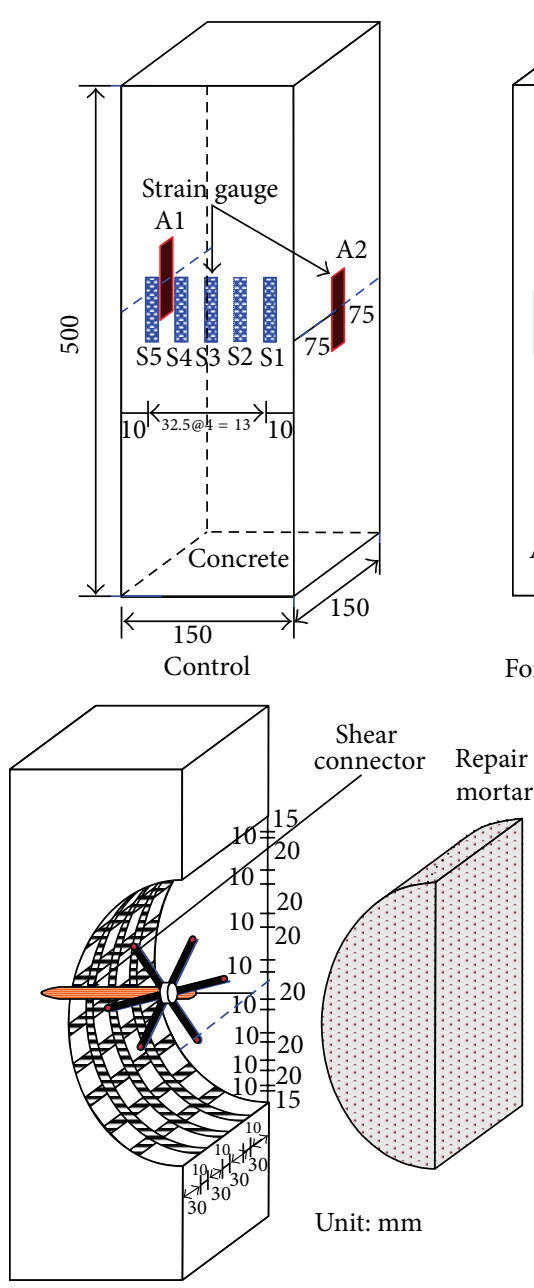

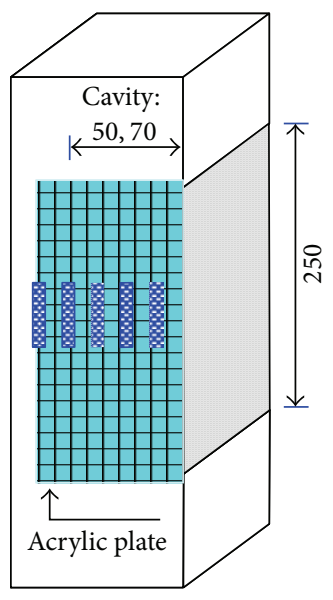

Form: acrylic plate

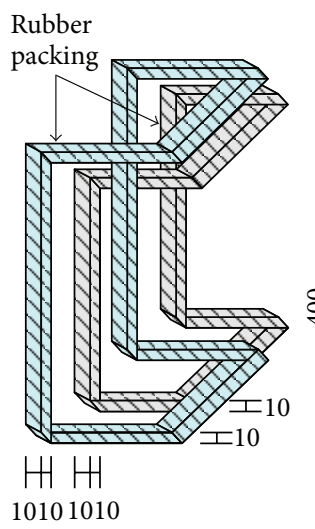

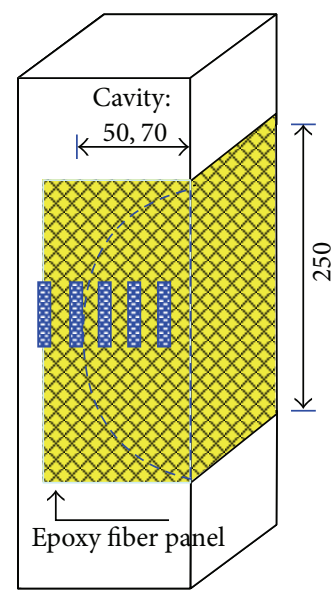

Form: epoxy fiber panel

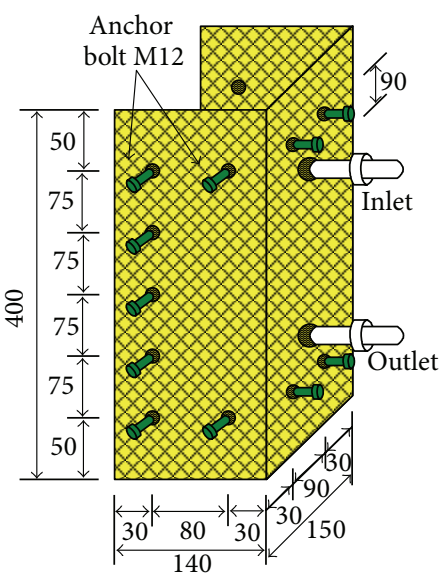

FIGURE 3: Column details.

TABLE 3: Mix proportion and mechanical properties of polymer mortar.

(a) Mix proportion

\begin{tabular}{lccc}
\hline $\begin{array}{l}\text { Cement/sand } \\
\text { (by weight) }\end{array}$ & $\begin{array}{c}\text { Polymer/cement } \\
(\%)\end{array}$ & $\begin{array}{c}\text { Water/cement } \\
(\%)\end{array}$ & $\begin{array}{c}\text { Flow } \\
(\mathrm{mm})\end{array}$ \\
\hline $1: 2$ & 20 & 32 & 168
\end{tabular}

(b) Mechanical properties

\begin{tabular}{lccc}
\hline $\begin{array}{l}\text { Curing } \\
\text { condition }\end{array}$ & $\begin{array}{c}\text { Compressive } \\
\text { strength }(\mathrm{MPa})\end{array}$ & $\begin{array}{c}\text { Tensile strength } \\
(\mathrm{MPa})\end{array}$ & $\begin{array}{c}\text { Elastic modulus } \\
(\mathrm{MPa})\end{array}$ \\
\hline $\begin{array}{l}\text { Atmospheric } \\
\text { curing }\end{array}$ & 52.6 & 2.6 & 24515.0 \\
\begin{tabular}{l} 
Water curing \\
\hline
\end{tabular} & 58.1 & 2.3 & 25662.0 \\
\hline
\end{tabular}

wrapped up on three sides, and holes were made to insert anchor bolts underwater repair materials through them. The shear connector that was installed at the center of the repair sections to resist shear force from the repair sections, and to prevent the elimination of the repair material, is

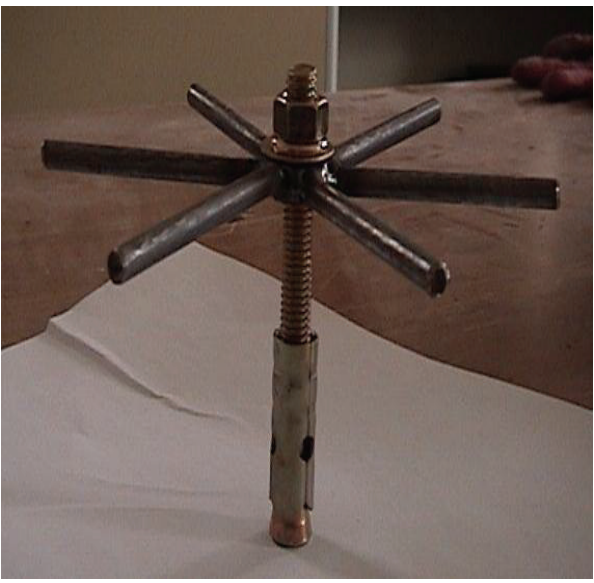

FIgURE 4: Shear connector.

shown in Figure 4. Also, the dimensional and mechanical characteristics of the shear connector are shown in Table 4. 
TABLE 4: Dimensions and mechanical properties of shear connector.

\begin{tabular}{lccccc}
\hline Type of anchor bolt & $\begin{array}{c}\text { Length } \\
(\mathrm{mm})\end{array}$ & $\begin{array}{c}\text { Diameter } \\
(\mathrm{mm})\end{array}$ & $\begin{array}{c}\text { Diameter of umbrella } \\
\text { ribs }(\mathrm{mm})\end{array}$ & Tensile strength (MPa) & Pullout strength (MPa) \\
\hline M10 & 100 & 10 & 120 & 293 & 25 \\
\hline
\end{tabular}

TABLE 5: Significant values for load and strain at ultimate state.

\begin{tabular}{|c|c|c|c|c|c|c|c|}
\hline \multirow{2}{*}{\multicolumn{2}{|c|}{ Column }} & \multicolumn{3}{|c|}{ Ultimate load } & \multicolumn{3}{|c|}{ Strain at ultimate load } \\
\hline & & $\begin{array}{c}\text { Measured } \\
(\mathrm{kN})\end{array}$ & \multirow{3}{*}{$\begin{array}{c}\begin{array}{c}\text { Average } \\
(\mathrm{kN})\end{array} \\
558.0\end{array}$} & \multirow{3}{*}{$\begin{array}{c}\text { Ratio } \\
1\end{array}$} & \multirow{3}{*}{$\begin{array}{c}\text { Measured } \\
(\mu \varepsilon) \\
2079.1 \\
1947.2\end{array}$} & \multirow{3}{*}{$\begin{array}{c}\text { Average } \\
(\mu \varepsilon)\end{array}$} & \multirow{3}{*}{$\begin{array}{c}\begin{array}{c}\text { Ratio } \\
- \\
1\end{array} \\
\end{array}$} \\
\hline \multirow{2}{*}{ Control } & M1 & 555.1 & & & & & \\
\hline & M2 & 560.9 & & & & & \\
\hline \multirow{8}{*}{ Repaired (ground) } & G-D-D1-1 & 513.9 & 513.9 & 0.92 & 1312 & 1312.0 & 0.65 \\
\hline & G-D-D1-2 & 554.1 & 554.1 & 0.99 & 2235.5 & 2235.5 & 1.11 \\
\hline & G-D-D2-1 & 518.7 & 518.7 & 0.93 & 1466.7 & 1466.7 & 0.73 \\
\hline & G-D-D2-2 & 544.3 & 544.3 & 0.98 & 2223.3 & 2223.3 & 1.10 \\
\hline & G-D-F-D1-1 & 567.8 & \multirow{2}{*}{568.8} & \multirow{2}{*}{1.02} & 2740.5 & \multirow{2}{*}{2798.6} & \multirow[t]{2}{*}{1.39} \\
\hline & G-D-F-D1-2 & 569.8 & & & 2856.6 & & \\
\hline & G-D-F-D2-1 & 551.1 & \multirow{2}{*}{549.2} & \multirow{2}{*}{0.98} & 2211.1 & \multirow{2}{*}{2235.3} & \multirow{2}{*}{1.11} \\
\hline & G-D-F-D2-2 & 547.2 & & & 2259.5 & & \\
\hline \multirow{12}{*}{ Repaired (underwater) } & U-W-F-D1-1 & 514.8 & \multirow{2}{*}{517.8} & \multirow{2}{*}{0.93} & 1899.9 & \multirow{2}{*}{1875.4} & \multirow{2}{*}{0.93} \\
\hline & U-W-F-D1-2 & 520.7 & & & 1850.9 & & \\
\hline & U-W-F-D2-1 & 527.6 & \multirow{2}{*}{529.6} & \multirow{2}{*}{0.95} & 1851.8 & \multirow{2}{*}{1851.4} & \multirow{2}{*}{0.92} \\
\hline & U-W-F-D2-2 & 531.5 & & & 1850.9 & & \\
\hline & U-D-F-D1-1 & N.A. & \multirow{2}{*}{519.8} & \multirow{2}{*}{0.93} & N.A. & \multirow{2}{*}{2115.3} & \multirow{2}{*}{1.05} \\
\hline & U-D-F-D1-2 & 519.8 & & & 2115.3 & & \\
\hline & U-D-F-D2-1 & 506 & \multirow{2}{*}{509.5} & 0.91 & 2139.3 & 2164.3 & 1.08 \\
\hline & U-D-F-D2-2 & 512.9 & & 0.91 & 2189.3 & 2104.3 & 1.08 \\
\hline & U-D,S-F-D1-1 & 578.6 & 564.9 & 1.01 & 2319.2 & 2409.6 & 1.20 \\
\hline & U-D,S-F-D1-2 & 551.1 & & & 2499.9 & & \\
\hline & U-D,S-F-D2-1 & 567.8 & 565.4 & 1.01 & 2043.2 & 2091.3 & 1.04 \\
\hline & U-D,S-F-D2-2 & 562.9 & 503.4 & 1.01 & 2139.3 & 207.0 & \\
\hline
\end{tabular}

3.5. Loading and Gauge Installation. To examine the stresses and deformations of the concrete and patch repair materials, gauges (A1, A2, S1, S2, S3, S4, and S5) were installed, as shown in Figure 3. A strain gauge was installed to measure the vertical strain of the existing section $\mathrm{Al}$ and the repaired section (the surface of epoxy fiber panel or repair material) A2. Furthermore, to compare strains at different locations in the interface between the existing concrete section and the repaired section, strain gauges were installed at S1 to S5. For loading device, a universal testing machine (UTM) with a capacity of $980 \mathrm{kN}$ was used, and the strain and load data of the concrete and forms were measured with a data logger.

\section{Test Results and Discussion}

To examine the repair effects of the underwater repair method applied to damaged underwater structures, a loading experiment was conducted. The measured maximum load (failure load) and the vertical strains of the concrete at the maximum load for each column are summarized in Table 5.

4.1. Failure Mode. The failure modes of the columns can be largely divided into interface failure at the interface between underwater repair materials and concrete and concrete failure. Interface failure occurs suddenly, as shown in Figures 5(a) and 5(b), when the repair sections were smooth, and when water was not removed from the forms and repair sections. These are undesirable failure modes in the repair and reinforcement of structures.

Concrete failures are illustrated in Figures 6(a) and 6(b). They occur in concrete with lower strength than repair materials, by the effect of the binding force of the forms, and the role of the shear connectors when the load shear at the interface is smooth. However, concrete failure would not occur in actual structures, because the repair sections are larger than the existing concrete sections. 


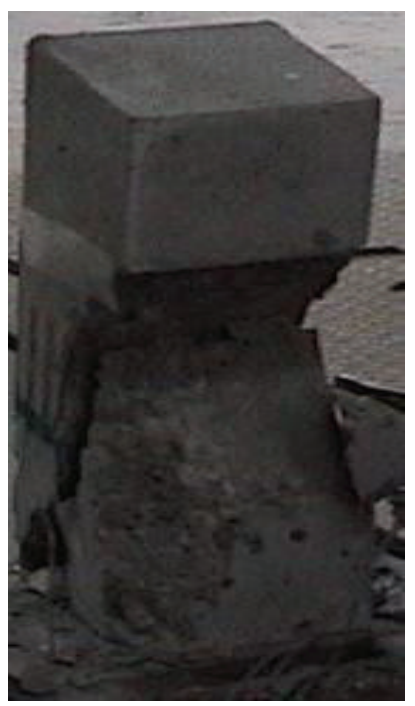

(a)

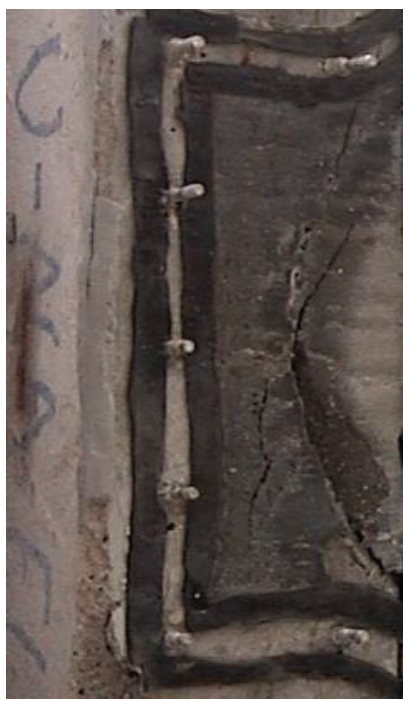

(b)

FIGURE 5: Interface failure.

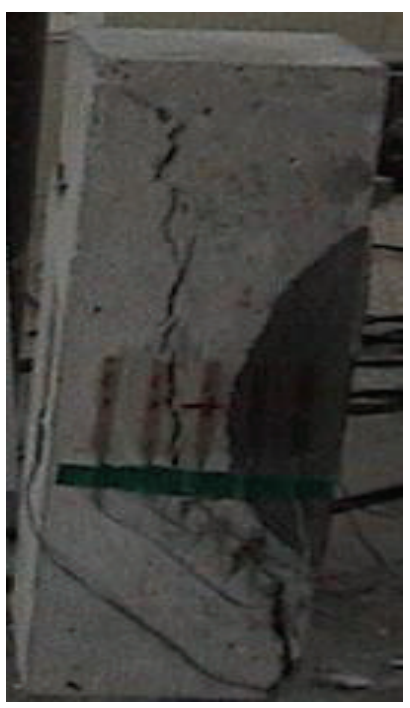

(a)

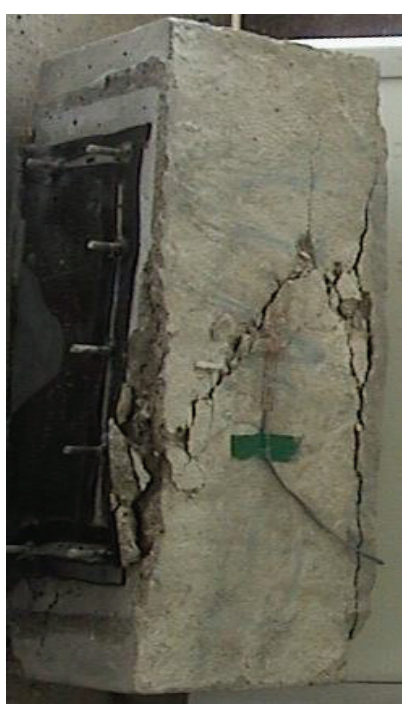

(b)
FIgURE 6: Concrete failure.

4.2. Control Columns. The maximum loads of control columns M1 and M2 were $555.1 \mathrm{kN}$ and $560.9 \mathrm{kN}$. The mean strains at maximum load measured at A1 and A2 of the columns were $2079 \mu \varepsilon$ and $1947 \mu \varepsilon$. These results are shown in Figure 7. Figure 8 shows the strains of M1 at S1 to S5. As the load increased, the strains were constant at various points on the side, and stress was evenly distributed on the shear surface of the concrete.

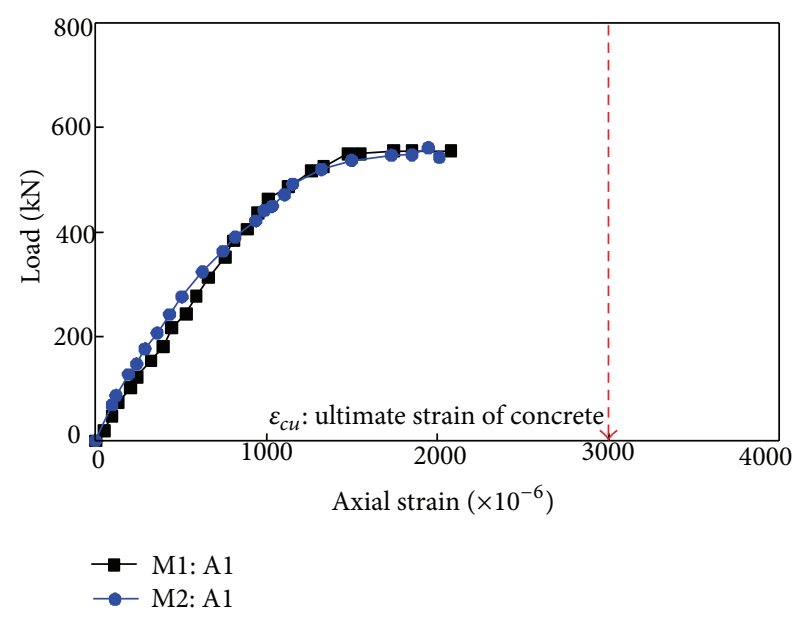

FIGURE 7: Load-axial strain curve: M1 and M2.

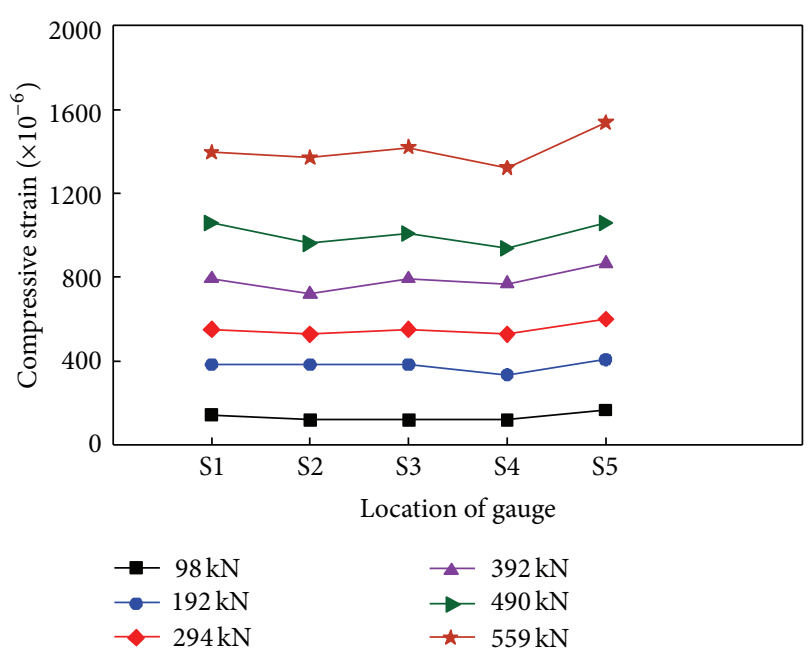

FIGURE 8: Strain distribution: M1.

\subsection{Repaired Columns}

4.3.1. $G-D-D$ Series. The results of the loading experiment on the repaired columns G-D-D series are shown in Figures 9 and 10. The axial strains of concrete at maximum load A1 and A2 of the columns G-D-D1-1 and G-D-D2-1 with smooth repair sections were $1312 \mu \varepsilon$ and $1466 \mu \varepsilon$, respectively, which were lower than the strain at maximum load of the control columns. The reason for this result is that the columns did not fail by the failure of the concrete or repair material, but by sudden interface failure, due to decreased bond strength at the interface.

For columns G-D-D1-2 and G-D-D2-2 whose repair sections were surface treated (chipping), the strain of the concrete surface reached the maximum compressive strain, and the columns failed by concrete failure. The reason for this result is that the interface failure did not occur due 


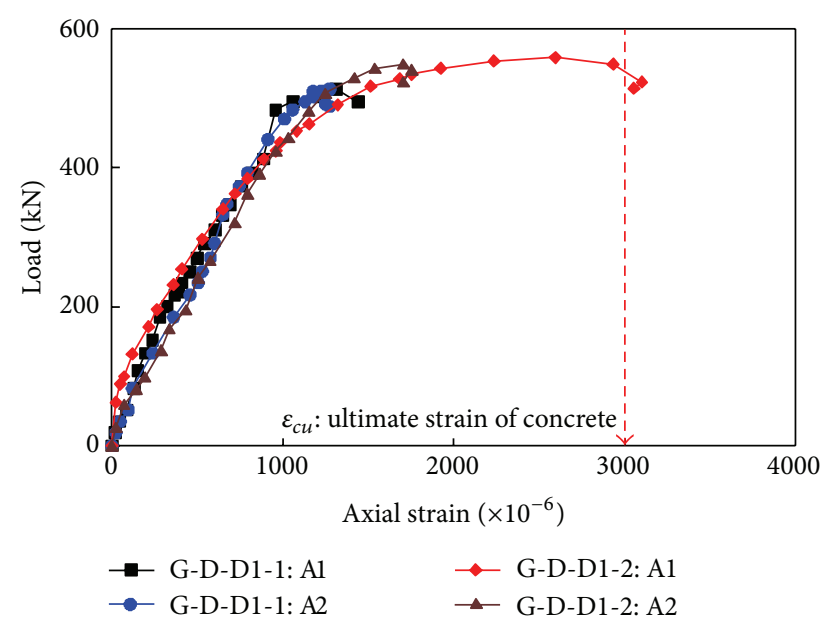

FIGURE 9: Load-axial strain curve: G-D-D1 columns.

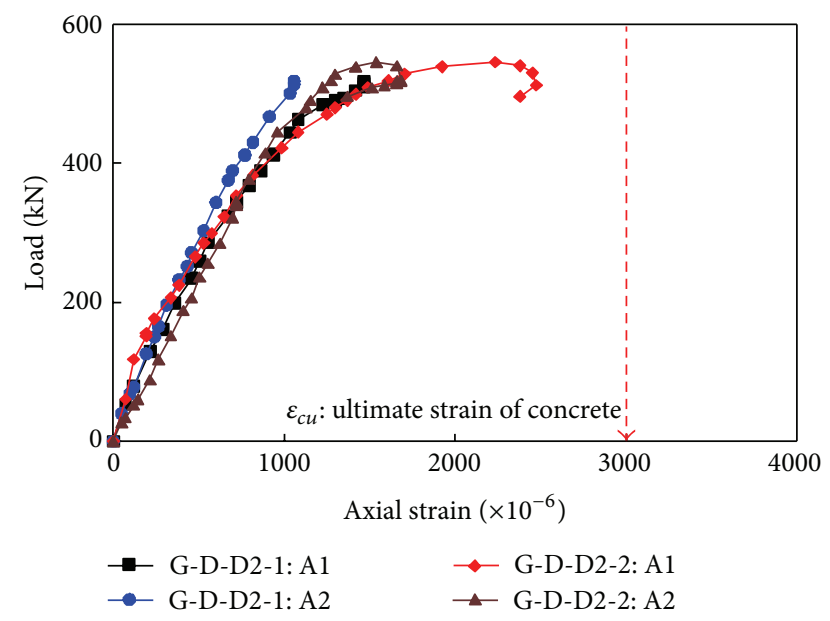

Figure 10: Load-axial strain curve: G-D-D2 columns.

to increased bond strength by the surface treatment of the repair sections and the excellent dynamic characteristics of the repair materials, and the load was concentrated on the concrete with lower strength. It was found that chipping of the repaired section increased maximum load by $8 \%$ and the strain at maximum load by $70 \%$. These results were similar, regardless of the degree of damage.

Figure 11 shows the strains of the column with smooth surface of repair sections and the chipped column. For the smooth surface column, the strain steadily increased up to $392 \mathrm{kN}$ at various locations but rapidly increased in weak concrete from $490 \mathrm{kN}$ until failure. However, for the chipped column, strain steadily increased to $490 \mathrm{kN}$ and then rapidly increased in concrete at failure. The reason for this is that the bond strength between concrete and repair material increased by the surface treatment of the repair sections, and the load was smoothly transmitted through the interface. As
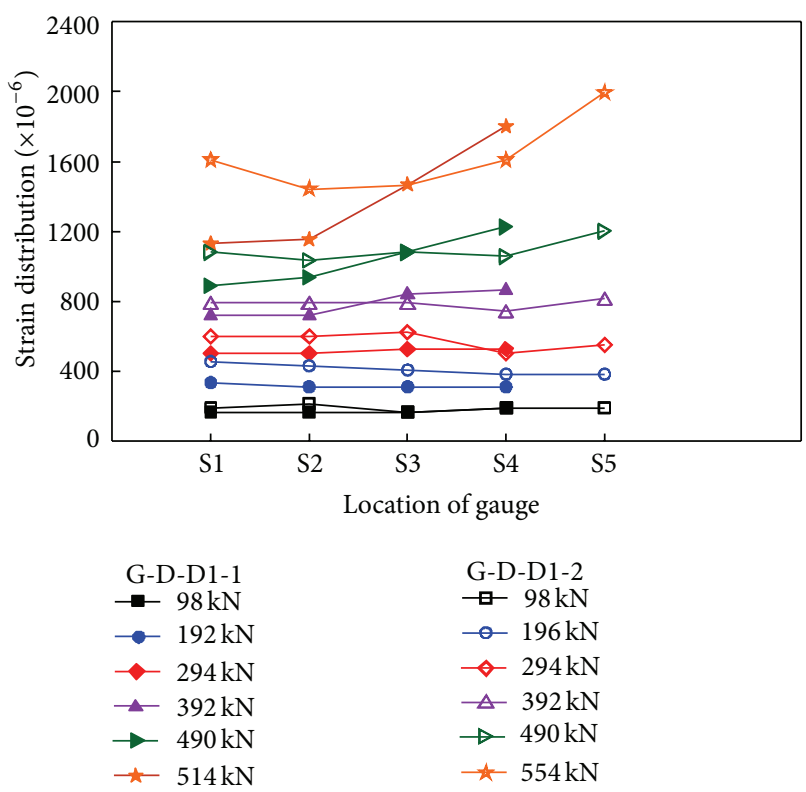

FIGURE 11: Strain distribution: G-D-D1 columns.

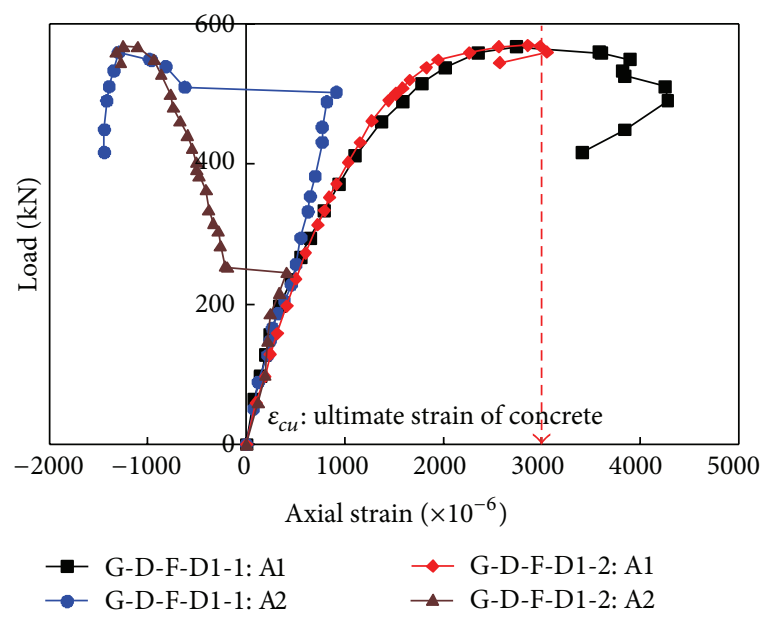

FIgURE 12: Load-axial strain curve: G-D-F-D1 columns.

a result, no interface failure occurred, but the weak concrete failed suddenly, as cracks were generated by the increased strain. This result indicates that the surface treatment for damaged sections of structures has great influence on repair effects. Repair materials with different material characteristics exhibited different behaviors. Austin and Robins [19] and Emberson and Mays [20] also found similar results.

4.3.2. G-D-F-D Series. As shown in Figure 12, the maximum load of the column G-D-F-D1-1 was $567.8 \mathrm{kN}$, and the strains of the fiber panel form of the repaired surface and the concrete surface showed similar behaviors until $294.2 \mathrm{kN}$. At 


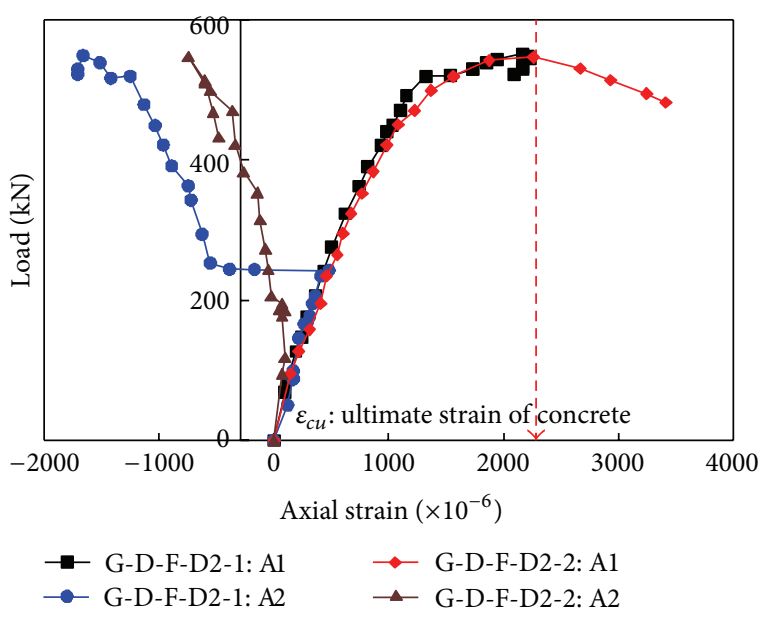

FIGURE 13: Load-axial strain curve: G-D-F-D2 columns.

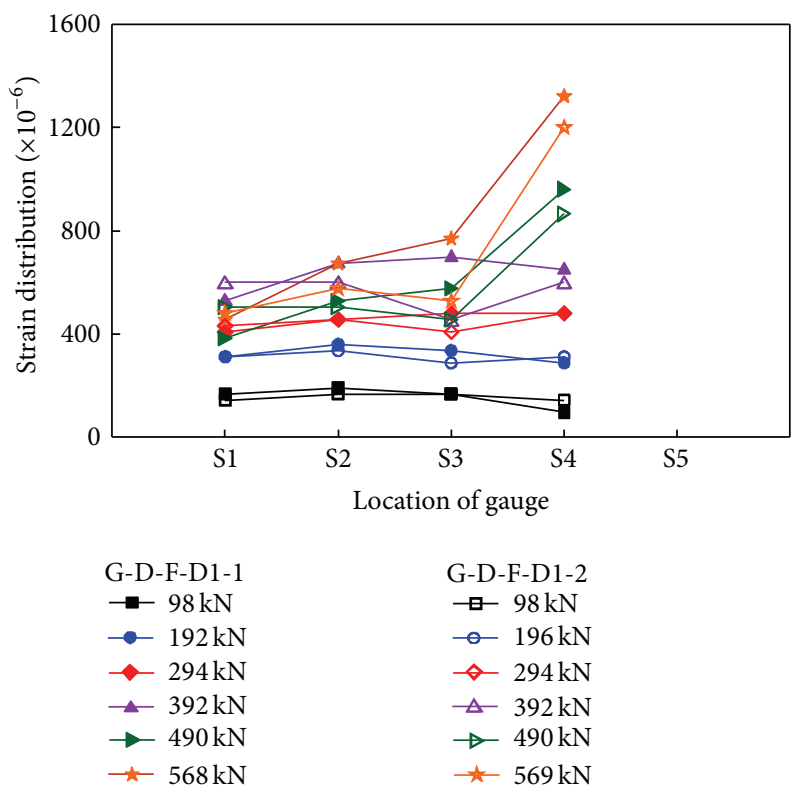

FIGURE 14: Strain distribution: G-D-F-D1 columns.

$500.1 \mathrm{kN}$, the strain changed to the tensile region simultaneously with the failure of the epoxy finishing at the joint of the forms, and binding force was exhibited until the column reached the maximum load. For the column G-D-F-D1-2, as shown in Figure 12, the strain of the form changes to the tensile region at $245.2 \mathrm{kN}$. This difference between columns in the load at which the strain of the form changes to the tensile region seems to be due to work errors of the epoxy.

Figure 13 shows the results of the columns G-D-F-D21 and G-D-F-D2-2. It can be seen that the epoxy fiber panel form is changed from compressed condition to tensile condition at $242.2 \mathrm{kN}$ and $196.1 \mathrm{kN}$, and the binding force is exhibited until the columns reach the maximum load.

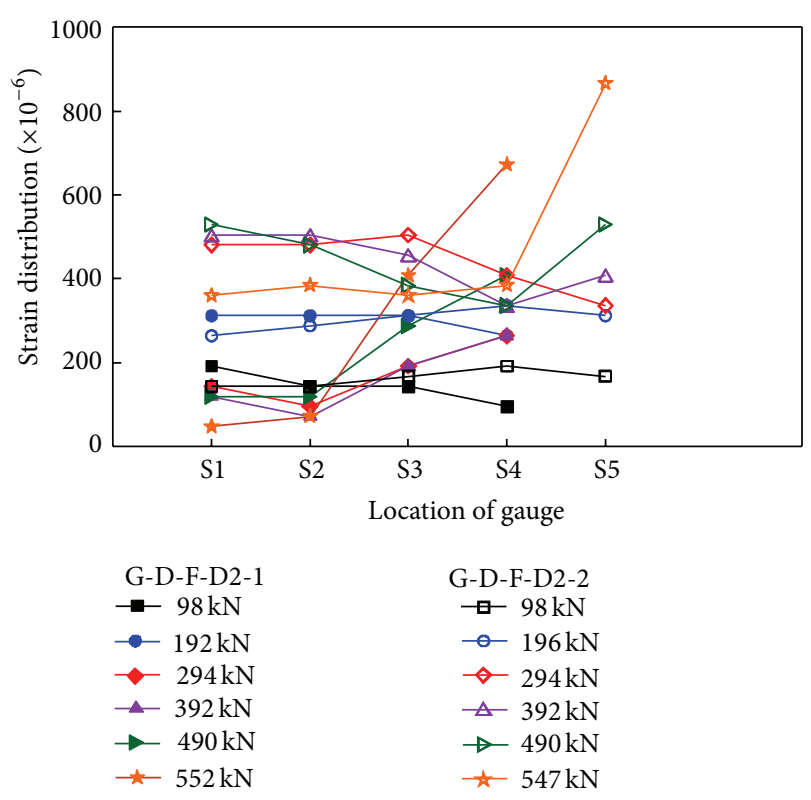

FIGURE 15: Strain distribution: G-D-F-D2 columns.

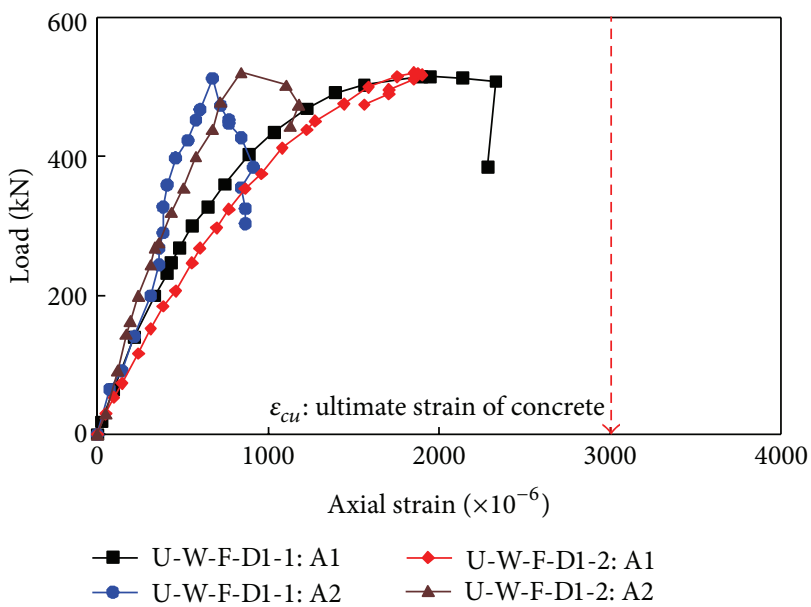

FIGURE 16: Load-axial strain curve: U-W-F-D1 columns.

As the load increases, the fiber panel form fixed to the column initially shows behaviors similar to concrete, but as the load increased further, the form binds the expanding concrete, and the axial strain of the form changes from the compressive region to the tensile region. Thus, the forms and the anchors that fix the forms exhibited binding force to the repair sections, and the maximum load increased more than that of the control columns. Furthermore, the strain of concrete also increased, and ductility increased greatly by the binding force of the forms, particularly in columns with a low degree of damage.

Figures 14 and 15 show the strains S1 to S5 by loading steps at different locations of the columns that were repaired 


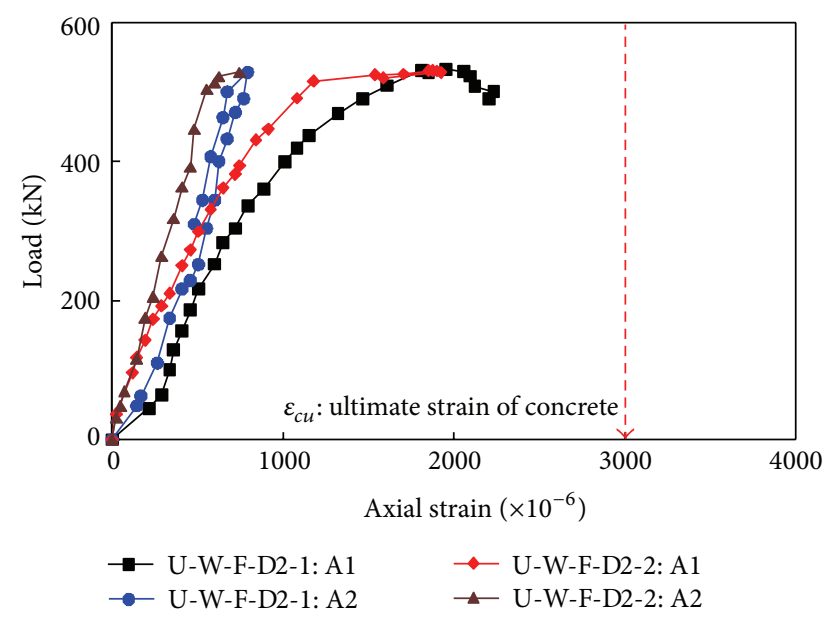

FIGURE 17: Load-axial strain curve: U-W-F-D2 columns.

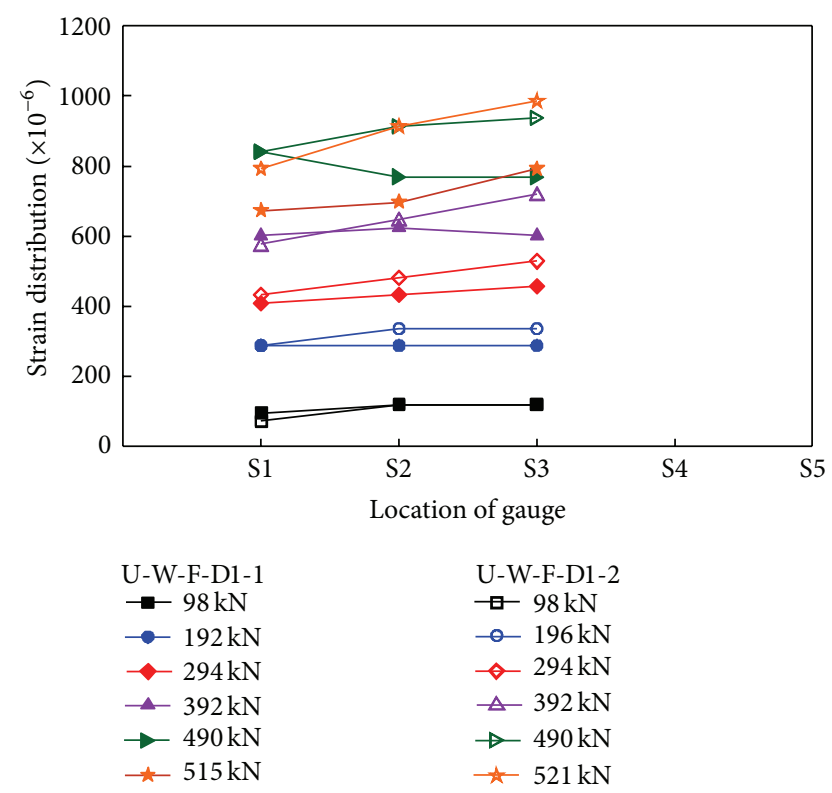

FIgURE 18: Strain distribution: U-W-F-D1 columns.

using fiber panel forms on the ground. No interface failure occurred due to the increased bond strength at the interface by chipping and the binding force of the fiber panel forms and anchor bolts. However, when the load increased over $490.3 \mathrm{kN}$, the strain of concrete rapidly increased, and failure occurred at the load of $539.4 \mathrm{kN}$ or higher. The reason for this result seems to be that the bond strength at the interface increased by chipping, and the binding force of the forms and anchors inhibited expansion and failure, thus improving the repair effects.

4.3.3. U-W-F-D Series. The loading experiment results for the columns U-W-F-D series are shown in Figures 16 and 17. The

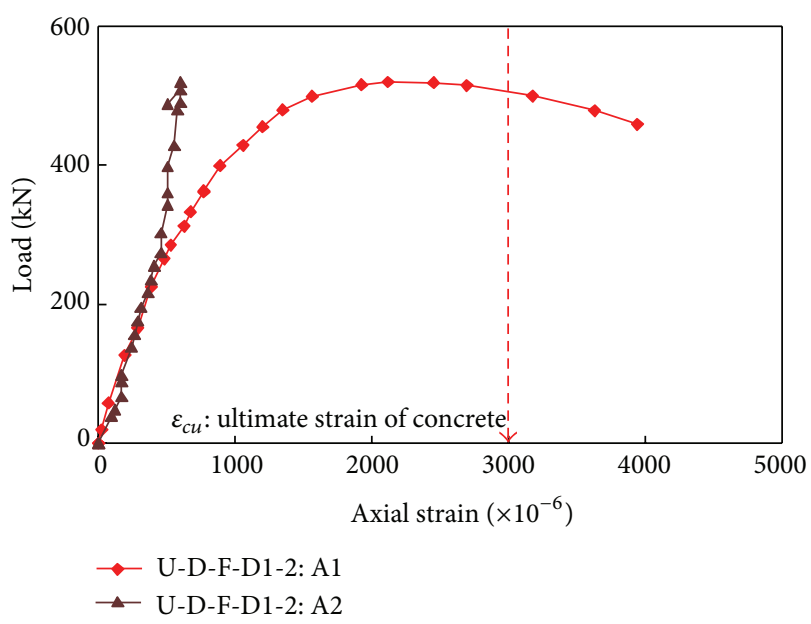

FIGURE 19: Load-axial strain curve: U-D-F-D1-2 column.

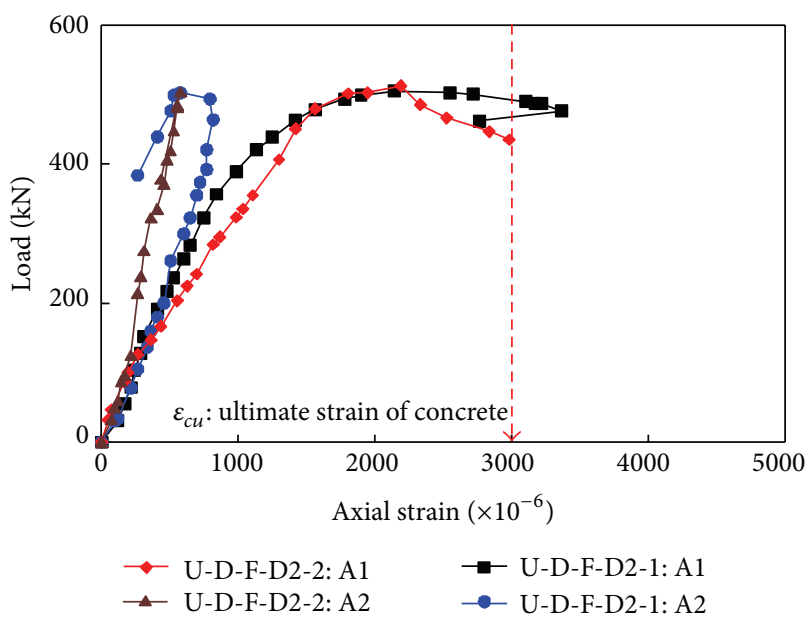

FIgURE 20: Load-axial strain curve: U-D-F-D2 columns.

columns failed at the maximum load of 509.9 to $529.6 \mathrm{kN}$, and the axial strain $\mathrm{Al}$ at maximum load was $1850 \mu \varepsilon$ to $1899 \mu \varepsilon$, smaller than that of the control column.

Unlike the results for the columns produced on the ground (G-D-F-D series), the strain of the epoxy fiber panel forms of the columns produced under water was measured in compressed condition until failure.

These results seem to have been caused by the special underwater working condition. In other words, for the forms to exhibit definite binding forces, the repair materials and the existing concrete sections must be completely bonded, and the load must be transmitted smoothly. However, due to the underwater working condition, the water in the forms reduced the bonding force between the repair materials and the repair sections, and interface failure developed before the forms exhibited binding force. 


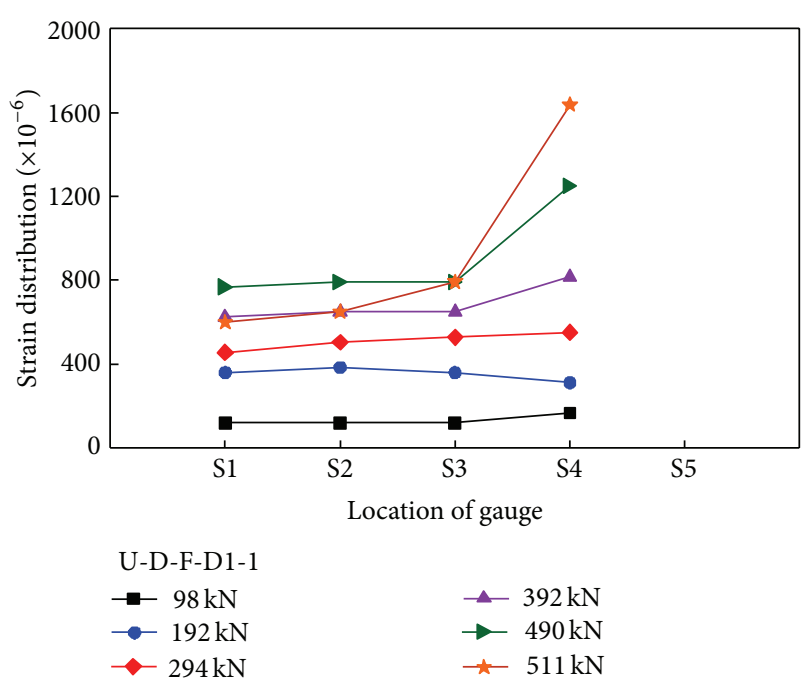

FIgURE 21: Strain distribution: U-D-F-D1-1 column.

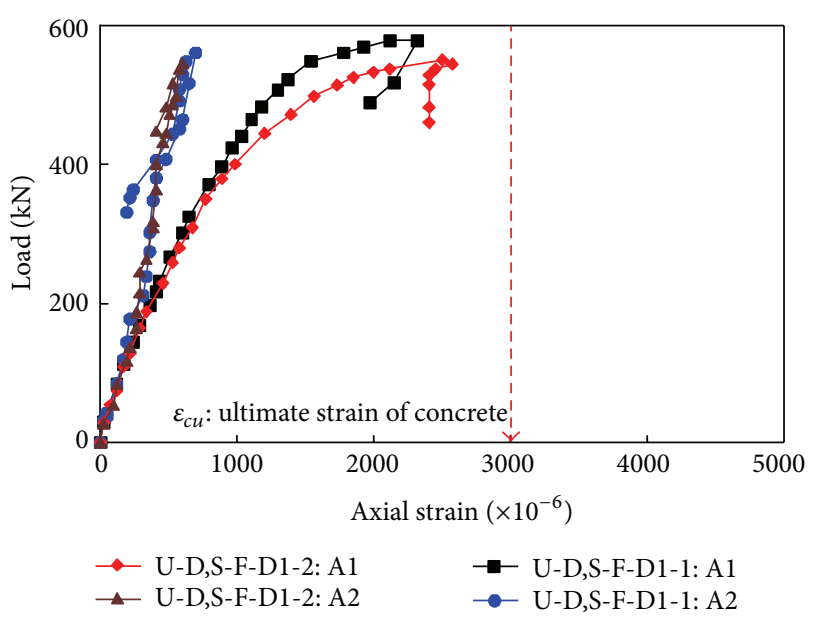

Figure 22: Load-axial strain curve: U-D,S-F-D1 columns.

Therefore, to improve the repair effects of underwater structures using forms, the water between repair sections and forms must be removed, so as to inhibit the washing and leaking of the patch repair materials.

Figure 18 shows the distribution of strains at different locations on the sides of the concrete and repair materials, for the columns U-W-F-D1. The changes of strains by increasing load at different locations were not clear, and the concrete and repair materials did not fail, either. The reason for this seems to be the occurrence of interface failure, which prevented the transmission of load to the repair sections, thus decreasing maximum load and strain.

4.3.4. U-D-F-D Series. The loading experiment results for the columns U-D-F-D series are shown in Figures 19 and 20. The maximum load of the repaired columns U-D-F-D series

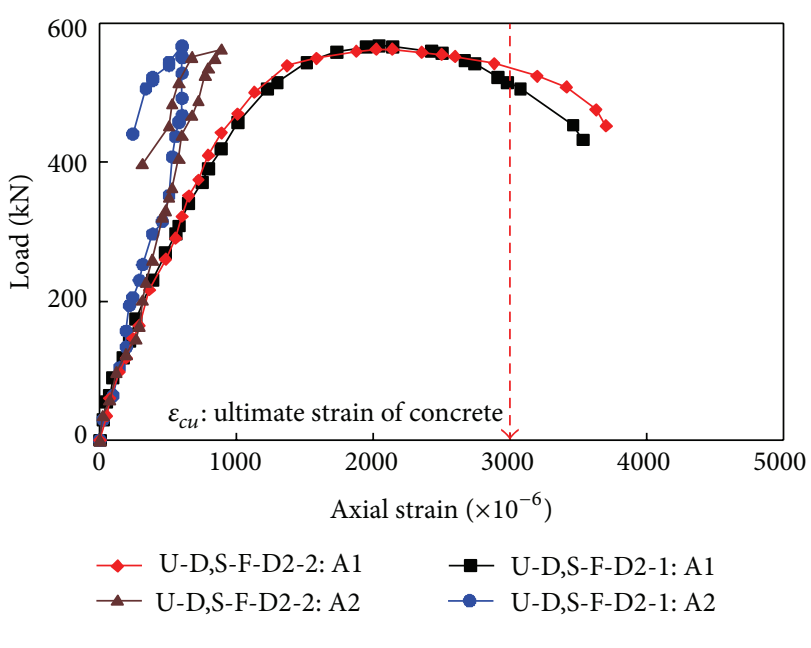

Figure 23: Load-axial strain curve: U-D,S-F-D2 columns.

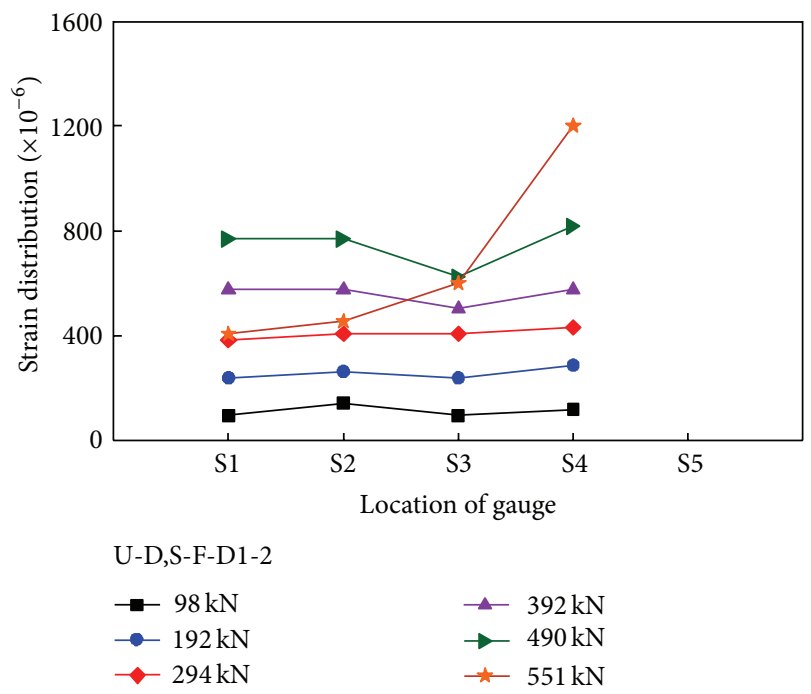

FIGURE 24: Strain distribution: U-D,S-F-D1-2 column.

ranged from 500.1 to $519.8 \mathrm{kN}$, which was lower by $7-9 \%$ than that of the control column. However, the strain of concrete was $2100 \mu \varepsilon$ or higher, by the binding force between forms and anchors.

Columns U-D-F-D series, which were repaired by underwater work, showed lower maximum loads, compared to the repaired columns produced by ground repair work. However, interface failure, which is important in repair works, did not happen. The reason for this seems to be that the proposed underwater repair method inhibited the interface failure between underwater repair materials and concrete, by the water removal process before injection of the underwater repair materials, and the water tightness provided by the epoxy fiber panel forms. 

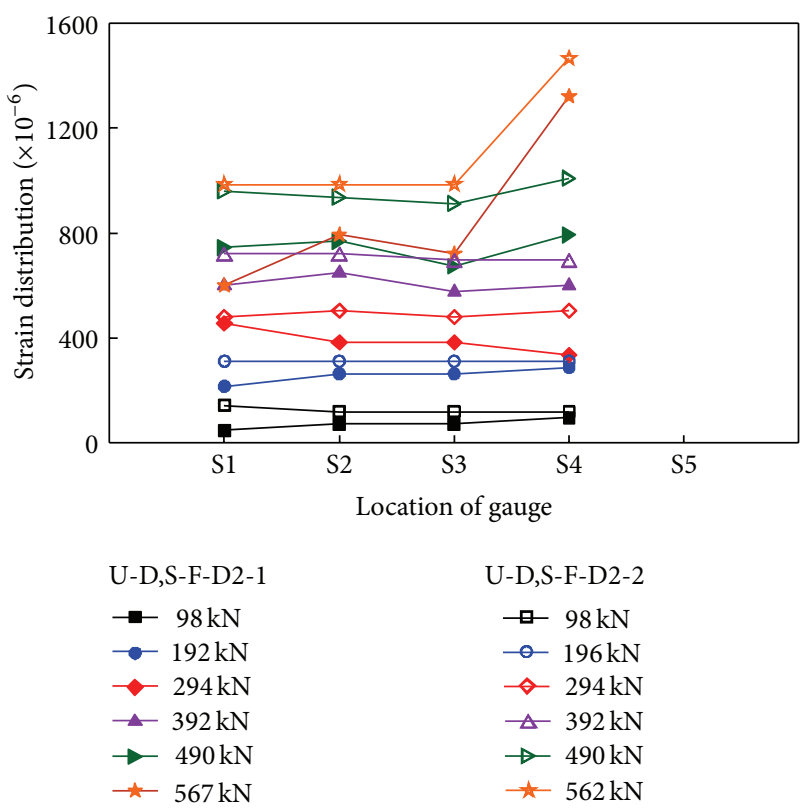

FIgURE 25: Strain distribution: U-D,S-F-D2 columns.

Figure 21 shows the strains at different locations on the sides of the underwater repair materials and concrete for the column U-D-F-D1-1. Concrete failure occurred at $509.9 \mathrm{kN}$, as strain on the concrete suddenly increased. In other words, the strains of concrete sections and repaired sections also steadily changed until failure. The reason for this seems to be that the water tightness by forms increased the bond force of the repaired sections and facilitated the smooth transmission of load. Removing the water from the forms and repair sections before injecting underwater repair materials inhibited the leaking and washing of the repair materials, thus increasing the bond force at the interface. Furthermore, the water tightness and binding force by forms were effective in underwater working conditions and increased the bonding force of the repair materials and concrete sections at the interface, thus improving repair effects.

4.3.5. U-D,S-F-D Series. The loading experiment results for the columns U-D,S-F-D series are shown in Figures 22 and 23. The maximum load of the columns U-D,S-F-D series was $559 \mathrm{kN}$ regardless of the maximum load, which is the same strength as that of the control column.

Furthermore, for the column that did not use shear connectors, concrete suddenly failed after the maximum load, and failure occurred at the interface of concrete and underwater repair materials. However, for the columns UD,S-F-F2-1 and U-D,S-F-F2-2, which used shear connectors, the maximum compressive strain of concrete increased to $3000 \mu \varepsilon$ or higher after the maximum load, showing a greatly improved strain capacity, and no interface failure occurred. The reason for this seems to be that the binding force of the forms and the shear connectors effectively resisted the interface failure between concrete and repair materials, greatly improving the ductility of the members.

Figures 24 and 25 show the strains at different locations of concrete and underwater repair materials. The vertical strain steadily increased with the increasing load, and the strain of concrete sections sharply increased at failure. The reason for this result seems to be that the binding and water tightness of the forms resisted the shear force at the interface of the underwater repair materials and concrete, thus inhibiting interface failure, and the load was evenly transmitted to the concrete sections and repaired sections, but the concrete sections that were relatively weaker failed.

\section{Conclusion}

This study applied an underwater repair method to the damaged sections of underwater structures to solve problems during underwater works and conducted experiments to demonstrate the repair effects. The study arrived at the following conclusions.

(1) The columns repaired with the proposed underwater repair method showed a maximum load that was similar to that of the control columns. This result seems to be due to the binding force of forms and anchors and the influence of the resistance of shear connectors at the interface between underwater repair materials and the existing concrete.

(2) The proposed underwater repair method fully removes water from the forms after installation of the forms and maintains perfect water tightness by the installation of rubber packings and the epoxy finishing after the installation of forms. As a result, the underwater repair materials are injected when the repaired sections are in dry condition, so they are not subject to the washing, loss, or impact of the patch repair materials, thus increasing the bonding force of the interface and maximizing repair effects. Therefore, interface failure between patch repair materials and existing structures, which may result from a patch repair using heterogeneous materials, does not occur.

(3) The proposed underwater repair method improved repair effects by $4 \%$, as demonstrated by the comparison of strength between the control columns and the repaired columns, and also greatly improved ductility, as demonstrated by the comparison of strain at maximum load.

\section{Acknowledgment}

This work was supported by the Postdoctoral Research Program of Sungkyunkwan University (2012).

\section{References}

[1] A. C. I. Committee 546, Guide to Underwater Repair of Concrete, America Concrete Institute, Colo, USA, 2006. 
[2] I. Lasa, R. Powers, and R. Kessler, "Practical application of cathodic protection systems for reinforcing steel substructures in marine environment," in Proceedings of the International Seminar on Repair and Rehabilitation of Reinforced Concrete Structures, pp. 16-31, Maracaibo, Venezuela, May 1997.

[3] K. Han, S. Hong, and S. Park, "Seismic performance evaluation of retrofitted bridge by isolation bearings," Baltic Journal of Road and Bridge Engineering, vol. 4, no. 3, pp. 134-142, 2009.

[4] D. Y. Cho, S. K. Park, and S. N. Hong, "Bond-slip behavior of cfrp plate-concrete interface," Mechanics of Composite Materials, vol. 47, no. 5, pp. 529-538, 2011.

[5] K. B. Han, S. Hong, and S. K. Park, "RC slabs repaired and strengthened by alumina/polymer mortar and prestressing strands in the tension zone: experimental investigation under static and fatigue loadings," Mechanics of Composite Materials, vol. 48, no. 5, pp. 587-602, 2012.

[6] S. Hong and S. K. Park, "Effect of prestress levels on flexural and debonding behavior of reinforced concrete beams strengthened with prestressed carbon fiber reinforced polymer plates," Journal of Composite Materials, 2012.

[7] D. Cambel-Allen and H. Roper, Concrete Structures: Material, Maintenance and Repair, Concrete Design and Construction Series, Longman, Singapore, 1991.

[8] J. L. Ramírez, "Ten concrete column repair methods," Construction and Building Materials, vol. 10, no. 3, pp. 195-202, 1996.

[9] Departments of the Army and Air Force (Headquarters), "Repair of rigid pavements using epoxy-resin grouts, mortars, and concrete (ch 10)," TM 5-822-9/AFM 88-6, Washington, DC, USA, 1989.

[10] G. W. Depuy, "Polymer modified concrete-properties and applications," Construction Repair, vol. 10, no. 2, pp. 63-67, 1996.

[11] Y. Ohama, Handbook of Polymer-Modified Concrete and Mortars Properties and Process Technology, Noyes Publications, Park Ridge, NJ, USA, 1995.

[12] UEG, "The influence of methods and materials on the durability of repairs to concrete coastal and offshore structures," UEG Publication UR 36(CIRIA/UEG), London, UK, 1986.

[13] B. Herroelen, D. Van Gemert, and K. Brosen, "Repair and strengthening of a swimming pool roof structure using polymer concrete and CFRP laminates," in Proceedings of the 9th ICPIC, pp. 419-425, Bologna, Italy, 1998.

[14] V. A. Lissenko, "Durability and structure formation of polymer composites for restoration and conservation of ancient architectural heritage," in Proceedings of the 9 ICPIC, pp. 699-708, Bologna, Italy, 1998.

[15] K. S. Rebeiz, D. W. Fowler, and D. R. Paul, "Recycling plastics in polymer concrete for construction applications," Journal of Materials in Civil Engineering, vol. 5, no. 2, pp. 237-248, 1993.

[16] G. Mullins, R. Sen, K. Suh, and D. Winters, "Underwater fiberreinforced polymers repair of prestressed piles in the Allen Creek Bridge," Journal of Composites for Construction, vol. 9, no. 2, pp. 136-146, 2005.

[17] J. Y. Yeom, Underwater Concrete Repairing, Lotte Engineering and Construction, Seoul, South Korea, 2005.

[18] S. Bazinet, L. Cereone, and F. Worth, "Composite FRP moves into underwater repair applications," SAMPE Journal, vol. 39, no. 3, pp. 8-16, 2003.

[19] S. A. Austin and P. J. Robins, "Development of patch test to study behavior of shallow concrete patch repairs," Magazine of Concrete Research, vol. 45, no. 164, pp. 221-229, 1993.
[20] N. K. Emberson and G. C. Mays, "Significance of property mismatch in the patch repair of structural concrete-part 2: axially loaded reinforced concrete members," Magazine of Concrete Research, vol. 48, no. 1, pp. 45-57, 1996. 

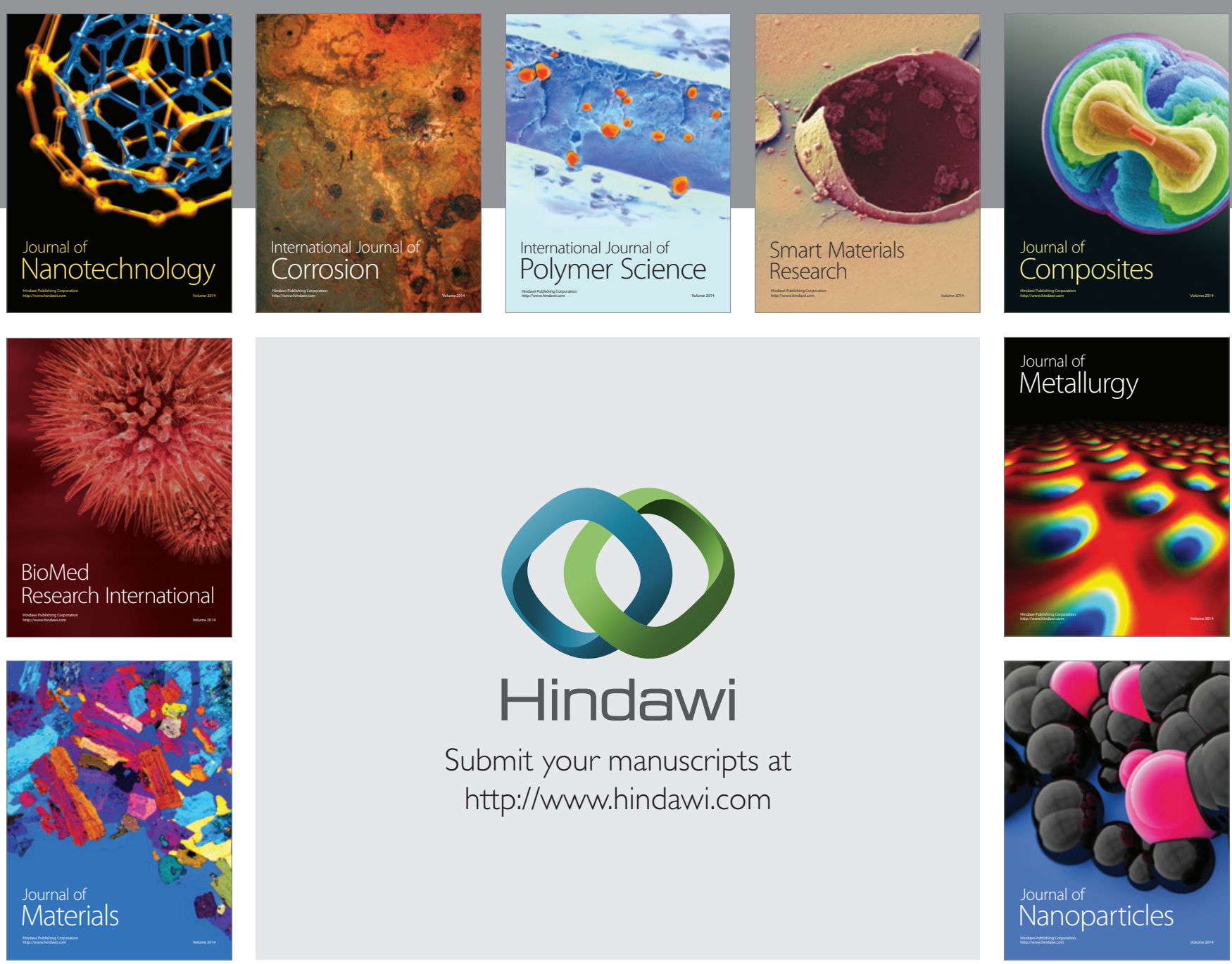

Submit your manuscripts at http://www.hindawi.com
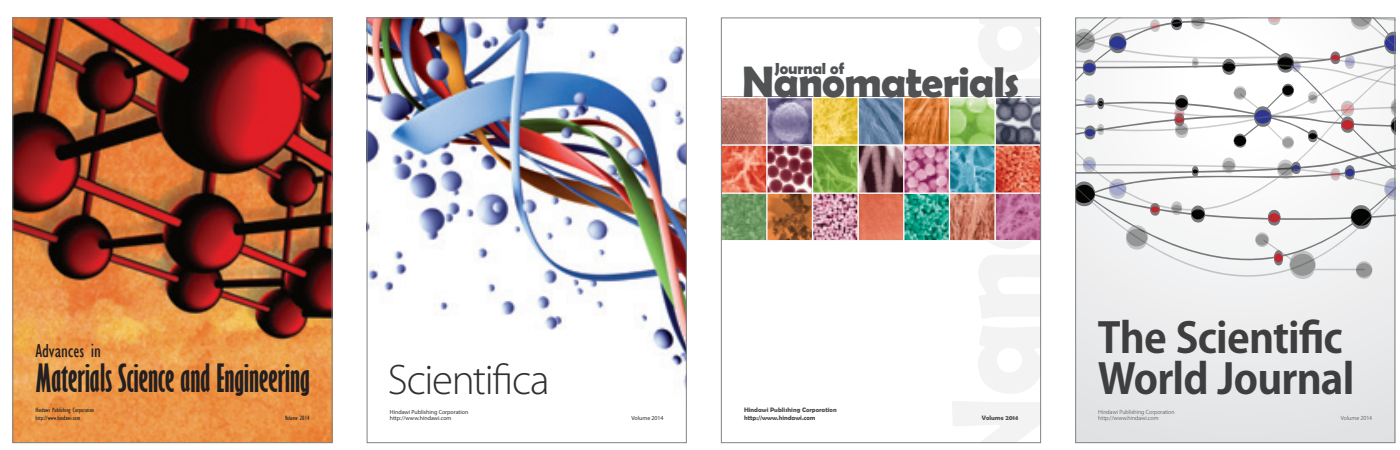

\section{The Scientific World Journal}
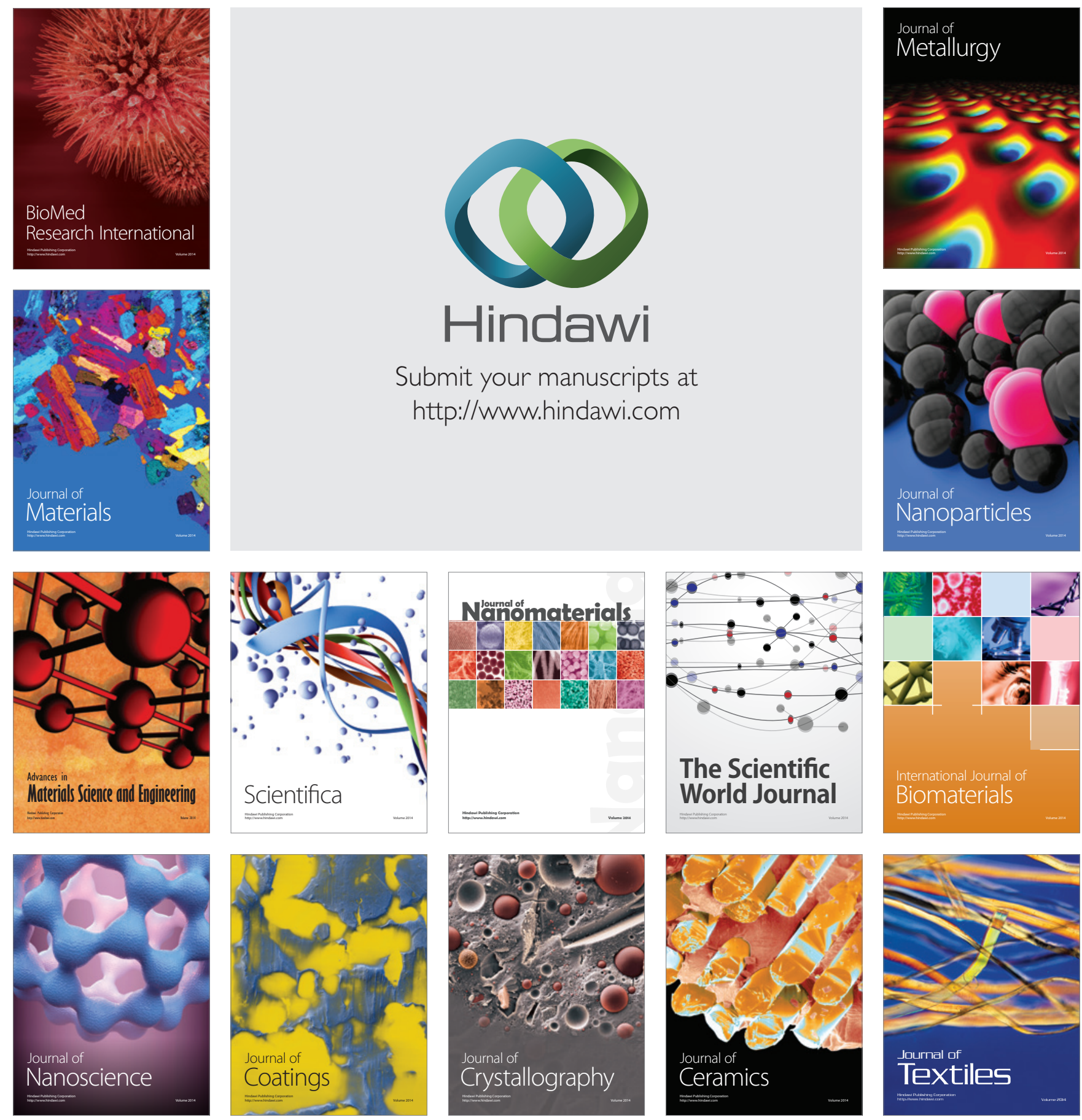